\title{
Association of maxillary dental developmental abnormality with precocious puberty: a case-control study
}

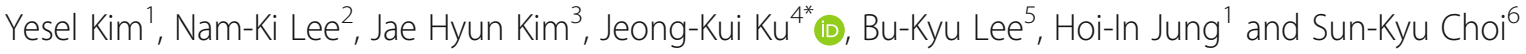

\begin{abstract}
Background: Dental studies of precocious puberty have focused on examination of jaw and dentition growth. The aim of the study was to analyze the relationship between precocious puberty and maxillary dental developmental abnormalities (DDAs).

Methods: This retrospective study was conducted on the Korean patients in whom dental panoramic and hand-wrist radiographs had been taken before they were 15 years of age. The maxillary DDAs were assessed as mesiodens, congenital missing teeth, peg-shape lateral incisors, or impacted teeth. The chronological ages of the control group members were within the normal range of the hand-wrist bone age. Others with a peak luteinizing hormone of $\geq 5$ and $<5 \mathrm{IU} / \mathrm{L}$ were allocated to central precocious puberty (CPP) and peripheral precocious puberty (PPP), respectively. Results: Of the enrolled 270 patients, 195, 52, and 23 were allocated to the control, CPP, and PPP groups, respectively. The maxillary DDAs were significantly more prevalent in the CPP group than in the other groups. Among those with maxillary DDA, the mesiodens predominated. Age- and sex-adjusted multivariate analysis revealed maxillary DDA (odds ratio, 3.36; $95 \% \mathrm{Cl}, 1.60-7.05)$ and especially mesiodens (odds ratio, 5.52; $\mathrm{Cl}, 2.29-13.28$ ) to be significantly associated with CPP.

Conclusions: Maxillary DDAs were significantly more prevalent in the CPP group than in the PPP or control groups. Among the many types of maxillary DDAs, mesiodens was significantly associated with CPP and may be considered a predictor of the development of CPP.
\end{abstract}

Keywords: Dental developmental abnormality, Gonadotropin-releasing hormone, Mesiodens, Precocious puberty, Supernumerary tooth

\section{Background}

Precocious puberty (PP) has recently become a topic of social focus. PP can be identified by signs of pubertal development in girls aged $<8$ and in boys aged $<9[1]$. When the bone age-as determined using hand-wrist radiography by the Tanner-White or Greulich-Pyle atlas method [2]-is advanced compared to the chronological age, PP can be diagnosed differentially as central

\footnotetext{
* Correspondence: kujk123@gmail.com

${ }^{4}$ Department of Oral and Maxillofacial Surgery, Section of Dentistry, Armed Forces Medical Command, Armed Forces Capital Dental Hospital,

Seongnam-si 13634, Korea

Full list of author information is available at the end of the article
}

precocious puberty $(\mathrm{CPP})$ or peripheral precocious puberty (PPP) using a gonadotropin-releasing hormone stimulation test (GnRHST) [3-6].

Treatment of PPP is focused on the originated diseases such as congenital adrenal hyperplasia, McCuneAlbright syndrome, severe hypothyroidism, disorders of the adrenal gland, tumors of the ovary or testis, and rare genetic syndromes [4]. On the other hand, the goal of treatment for CPP patients can be considered to match pubertal development with their peers to reduce the psychosocial problems and minimize the loss of growth potential. In patients with CPP, delayed treatment may result in growth loss and socio-psychological problems,

\section{Springer Open}

(๑) The Author(s). 2020 Open Access This article is licensed under a Creative Commons Attribution 4.0 International License, which permits use, sharing, adaptation, distribution and reproduction in any medium or format, as long as you give appropriate credit to the original author(s) and the source, provide a link to the Creative Commons licence, and indicate if changes were made. The images or other third party material in this article are included in the article's Creative Commons licence, unless indicated otherwise in a credit line to the material. If material is not included in the article's Creative Commons licence and your intended use is not permitted by statutory regulation or exceeds the permitted use, you will need to obtain permission directly from the copyright holder. To view a copy of this licence, visit http://creativecommons.org/licenses/by/4.0/. 
such as emotional distress and problem behavior, because hormonally caused behavioral changes (e.g., aggression) may break out earlier in patients with CPP [7, 8]. Therefore, many studies have been conducted to identify the predictive factors of CPP which has been attributed to a dysfunction of the hypothalamic-pituitarygonadal axis. As a result, endocrine-disrupting BMI [6], chemicals [7], central nervous (CNS) problems, or head trauma [8] have been suggested to be predictors of the future development of CPP.

At the chronologic age of six to seven, before puberty begins, mixed dentition starts as the deciduous teeth which are replaced with permanent teeth. Since the timing of PP diagnosis is an important dental turning point, many researches have been conducted on the relationship between PP and dental development such as tooth eruption, tooth growth, and jaw growth [9-12]. However, the relationship between PP and the dental parameter is controversial because the above parameters vary, even in individuals without PP.

Dental developmental abnormalities (DDAs) are evidenced by an abnormal tooth shape or number such as peg-shaped maxillary lateral incisors (peg-lateralis), congenital missing tooth, impacted maxillary permanent teeth, germinated tooth, fused tooth, twinned tooth, taurodontism, or supernumerary teeth. The DDAs are more common in the maxillae than mandibles [13, 14]. Of these DDAs, supernumerary teeth are usually encountered in the anterior maxillae and are called mesiodens [14]. No association between mesiodens and other DDAs has been reported whereas peg-lateralis, congenital missing lateral incisors, and impacted canines are interrelated $[15,16]$. Before the identification of pubertal development, most DDAs can be diagnosed easily using dental radiographs. And the DDAs are recommended to treat approximately before maxillary permanent incisor eruption (5 to 6 years of age) [17].

Both maxillary teeth and the anterior pituitary gland, the latter of which secretes follicle-stimulating hormone (FSH), luteinizing hormone ( $\mathrm{LH}$ ), and growth hormone $(\mathrm{GH})$, are embryologically derived from the oral epithelium. Therefore, maxillary DDA may be embryologically associated with PP. In addition, maxillary DDA may be a valuable predictor of a diagnosis of PP because they can be identified before the onset of pubertal development. The aim of this study was to identify the relationship between maxillary DDA and PP.

\section{Materials and methods}

This case-control study was conducted on patients in whom dental panoramic and hand-wrist radiographs had been taken between March 2008 and May 2018, at the department of pediatrics or dentistry in Seoul National University Bundang Hospital. The inclusion criteria were as follows: (1) age between 3 and 15 years when both dental panoramic and hand-wrist radiographs were taken and a hand-wrist evaluation for bone age using the Greulich-Pyle atlas method [2]. (2) The presence of GnRHST results in a patient with advanced bone age compared to the chronological age. The exclusion criteria were as follows: history of orthodontic treatment, maxillofacial surgery, and the presence of dentofacialrelated deformity or syndrome.

The range of bone age was determined as by expert radiologists with the Greulich-Pyle atlas method. The control group consisted of patients in whom their chronological age within the range of bone age. Among other patients with an earlier bone age than the chronological age and breast budding or testicular enlargement, they were classified into the experimental groups (CPP and PPP groups) by GnRHST (described below). Gonadotropin-releasing hormone (GnRH, $100 \mu \mathrm{g}$; Relefact; Sanofi-Aventis, Frankfurt, Germany) was injected intravenously after obtaining baseline serum samples. Luteinizing hormone (LH) was measured by blood samples which were collected 30, 45, and 60 min after GnRH administration. The experimental group was divided into a CPP group with a peak LH concentration of $\geq 5 \mathrm{IU} / \mathrm{L}$ and a PPP group with a peak LH concentration of $<5$ IU/L [4].

Because the patients independently visited the department of dentistry and pediatrics, the pediatric evaluation age was defined as chronological age at the time when the hand-wrist radiograph was first examined, and the dental evaluation age was separately defined at the time when the first dental panoramic radiograph was taken. Statistical analysis was based on the dental evaluation age. In the dental panoramic radiographs, the maxillary DDAs were classified into mesiodens and the others, including impacted maxillary permanent teeth, congenital missing teeth, and peg lateralis, by an expert oral and maxillofacial surgeon (Fig. 1).

\section{Statistical methods}

The control, CPP, and PPP groups were determined using a chi-square or Fisher's exact test for the categorical variables or ANOVA for the continuous variables. Post hoc analysis was performed by Bonferroni correction. Statistical significance among the groups was evaluated according to the subtypes of maxillary DDAs (total maxillary DDAs, mesiodens, and other maxillary DDAs except for mesiodens). One to one propensity score matching to adjust for age and sex ratio was applied to the dataset of the control and CPP group. The significance of maxillary DDAs in predicting the development of the PP response was compared using both univariate and multivariate logistic regression analysis to adjust for age and sex ratio. The univariate and multivariate odds ratio with their $95 \%$ confidence intervals were calculated for the subtypes of maxillary DDAs. Two-sided $p$ values 

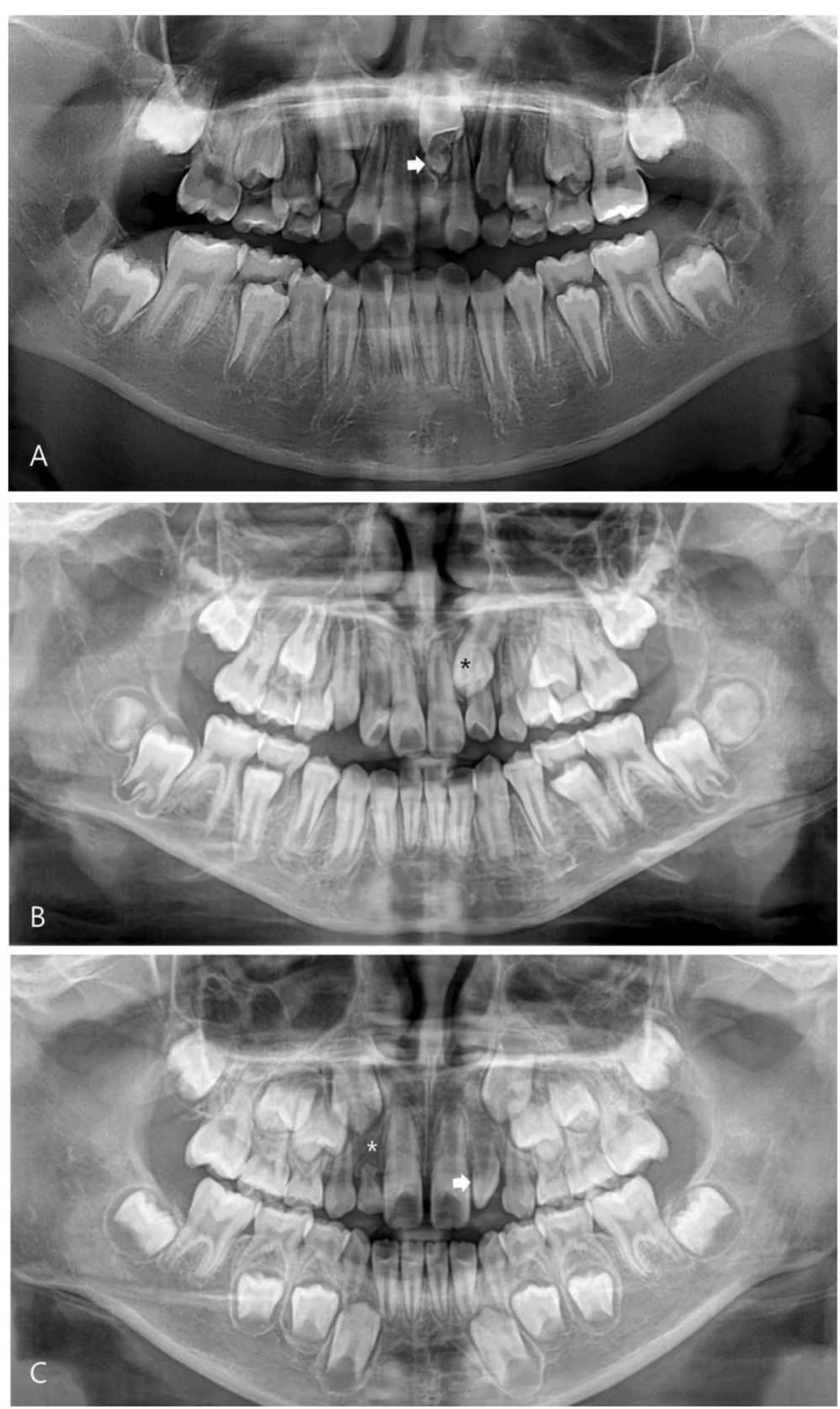

Fig. 1 Maxillary dental developmental abnormality. a Mesiodens (arrow). b Impacted maxillary canine (asterisk). c Congenital missing of the lateral incisor (asterisk) and peg lateralis (arrow)

of $<0.05$ were considered significant. The analysis was performed using SAS version 9.4 (SAS Institute, Cary, NC) and R 3.5. 1 (Vienna, Austria; http://www.R-project.org/).

\section{Ethics statement}

The study was reviewed and approved by the Institutional Review Board at Seoul National University Bundang Hospital (No. B-1904/535-106). It was granted an exemption of the informed consent due to the retrospective nature of this study.

\section{Results}

Two hundred and seventy patients (12.3 \pm 4.4 years) were enrolled in this study; 195, 52, and 23 were allocated to the control, CPP, and PPP groups, respectively (Fig. 2). The pediatric evaluations were performed earlier on average than the dental evaluations in all groups. CPP and PPP groups revealed significant intergroup differences in sex and age compared with control group (Table 1). 


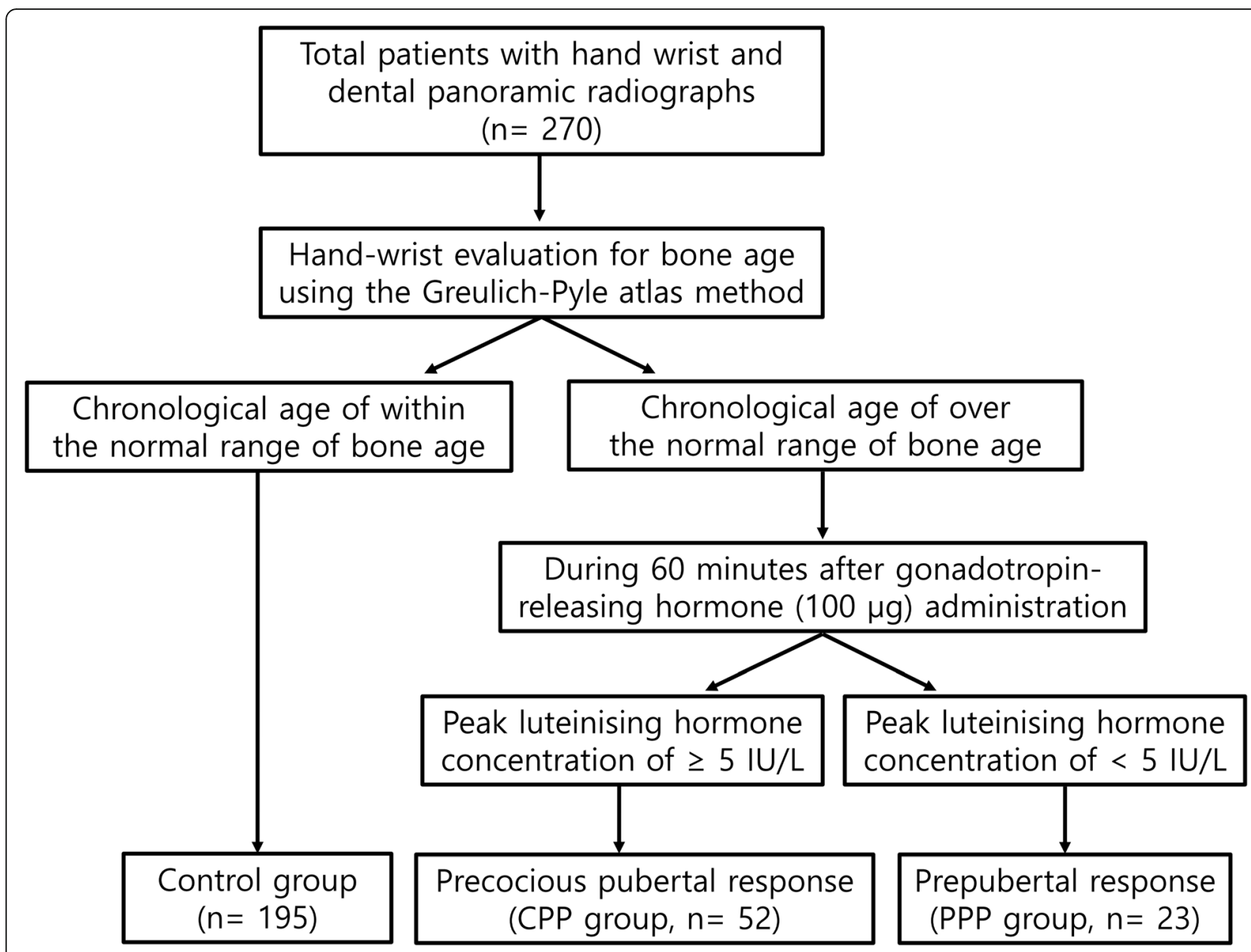

Fig. 2 Flow diagram of patient classification

The prevalence of maxillary DDA was significantly higher in the CPP group (50.00\%) than in the control $(22.05 \%)$ and PPP $(21.74 \%)$ groups $(P<0.05)$. Mesiodens was more prevalent in the CPP group $(42.31 \%)$ than in the control (13.33\%) and PPP $(21.74 \%)$ groups $(P<$ $0.05)$. But no intergroup difference was observed between the prevalence of the other maxillary DDAs, except for the mesiodens, in the PPP (0.00\%), CPP (7.69\%), and control $(8.71 \%)$ groups (Table 1$)$.

One-to-one propensity score matching was used to adjust for age and sex ratio, which differed in the control and CPP groups. The prevalence of maxillary DDAs were significantly different in the CPP $(50.00 \%)$ and control $(19.23 \%)$ groups $(P<0.001)$. The prevalence of mesiodens was significantly higher in the CPP group (42.31\%) than in the control group $(9.53 \%)(P<0.001)$. On the other hand, the prevalence of the other maxillary DDAs, except for mesiodens, was similar in the control (11.54\%) and CPP (7.69\%) groups (Table 2).

Univariate analysis and age- and sex-adjusted multivariate analysis revealed maxillary DDAs (odds ratio,
3.85; 95\% confidence interval, $1.92-6.92$ and 3.36 ; 1.60 7.05 , respectively), especially mesiodens (odds ratio, 4.98; 95\% confidence interval, $2.46-10.06$ and $5.52 ; 2.29$ 13.28 , respectively), to be associated with the precocious puberty response (Table 3 ).

\section{Discussion}

In this study, the relationship between maxillary DDAs and PP was firstly analyzed retrospectively. In general, it is important that children with CPP be identified from normal and PPP early because delayed diagnosis and the treatment of CPP leads to a loss of growth potential and psycho-social problems $[1,18]$. Many studies have been conducted to identify the screening or predictive factors of CPP. The relationship remains controversial between the CPP and dental factors such as dental maturity [10, 19], dental age [11], malocclusion [12], and mandibular growth pattern [10]. At time of PP onset, many children with mixed-dentition visited dental clinics to have their dental development evaluated. For this dental examination, the patients are radiographed to examine the 
Table 1 Demographic characteristics of the subjects and prevalence of maxillary dental developmental abnormalities in the three study groups

\begin{tabular}{|c|c|c|c|c|}
\hline No. & $\begin{array}{l}\text { Control group } \\
n=95\end{array}$ & $\begin{array}{l}\text { CPP group } \\
n=52\end{array}$ & $\begin{array}{l}\text { PPP group } \\
n=23\end{array}$ & $P$ \\
\hline Female (\%) & $109(55.9 \%)$ & $47(90.38 \%)$ & $23(100 \%)$ & $<.001^{\mathrm{a}}$ (Control vs CPP, PPP) \\
\hline \multicolumn{5}{|l|}{ Age (year) } \\
\hline Pediatric evaluation & $10.5 \pm 2.9$ & $8.3 \pm 0.5$ & $8.0 \pm 1.1$ & $\begin{array}{r}<.001^{\mathrm{b}} \text { (Control vs CPP) } \\
.023^{\mathrm{b}} \text { (Control vs PPP) }\end{array}$ \\
\hline Dental evaluation & $12.0 \pm 4.4$ & $8.9 \pm 2.3$ & $9.6 \pm 3.3$ & $<.001^{\mathrm{b}}$ (Control vs CPP, PPP) \\
\hline \multicolumn{5}{|l|}{ Prevalence } \\
\hline Maxillary DDAs & $43(22.05 \%)$ & $26(50.00 \%)$ & $5(21.74 \%)$ & $\begin{array}{l}<.001^{\mathrm{a}} \text { (Control vs CPP) } \\
1.000^{\mathrm{a}} \text { (Control vs PPP) } \\
<.029^{\mathrm{a}} \text { (CPP vs PPP) }\end{array}$ \\
\hline Mesiodens & $26(13.33 \%)$ & $22(42.31 \%)$ & $5(21.74 \%)$ & $\begin{array}{c}<.001^{\mathrm{a}} \text { (Control vs CPP) } \\
.732^{\mathrm{a}} \text { (Control vs PPP) } \\
<.049^{\mathrm{a}} \text { (CPP vs CPP) }\end{array}$ \\
\hline Except mesiodens & $17(8.71 \%)$ & $4(7.69 \%)$ & 0 & $0.317^{c}$ \\
\hline
\end{tabular}

Abbreviations: CPP central precocious puberty, DDAs dental developmental abnormalities, $P P P$ peripheral precocious puberty

${ }^{\text {a }}$ Post hoc analysis after chi-square test

${ }^{b}$ Post hoc analysis after ANOVA

${ }^{\mathrm{C}}$ Fisher exact test compared with control group

eruption of permanent teeth or identify the DDAs including supernumerary, impacted, and missing teeth. DDAs can be diagnosed clearly and efficiently using radiographs by the abnormality of shape or number of tooth [17]. The supernumerary tooth-mesiodens-occurs at the time of maxillary permanent tooth germ formation [20]. The enamel portion of the maxillary permanent anterior teeth is formed between 3 to 4 years of age, and the age of eruption of these teeth is commonly between 6 to 7 years of age. Therefore, DDA may be a predictive factor in the early diagnosis of CPP because DDA can be identified before the onset of signs of pubertal development.

Embryologically, the pituitary gland is an important structure for the migration of neural crest cells involved in oral formation [21]. The anterior pituitary gland has the same origin as oral neural crest cells. And the posterior pituitary gland has the same mesenchymal origin as the maxillofacial region [22]. The sella turcica forms a bony seat for the pituitary gland. Therefore, a sella turcica deformity has been reported to be associated with tooth developmental disorders

Table 2 Prevalence of maxillary dental developmental abnormalities in the control group and precocious pubertal response group after 1:1 propensity score matching $(n=52)$

\begin{tabular}{llll}
\hline & No. $(\%)$ & $P$ \\
\cline { 2 - 3 } & Control group & CPP group & \\
\hline Maxillary DDAs & $10(19.23 \%)$ & $26(50.00 \%)$ & $0.001^{\mathbf{a}}$ \\
Mesiodens & $4(7.69 \%)$ & $22(45.31 \%)$ & $<0.001^{\mathbf{a}}$ \\
Except mesiodens & $6(11.54 \%)$ & $4(15.38 \%)$ & $1^{\mathbf{b}}$
\end{tabular}

Abbreviations: CPP central precocious puberty, DDAs dental

developmental abnormalities

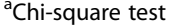

${ }^{\mathrm{b}}$ Fisher exact test including mesiodens [23-26]. In addition, an abnormality of the sella turcica has been proven to be related to tooth eruption by an analysis of the eruption timing and eruption disorders of the maxillary teeth according to the nerve distribution [22]. On the other hand, the effect of hormones remains controversial on tooth maturity or jaw growth. Some studies have reported a relationship between the hormones secreted by the pituitary gland and the development of dentition or jaw growth. Kjellberg et al. reported that patients with a GH deficiency exhibited delayed tooth eruption [27], and Cantu et al. reported that GH-deficiency patients showed a delayed bone age but no delay in dental age on the radiographs [28]. Others have reported that sexual maturity is not related to dental maturity [29], and a GH treatment has little effect on tooth development [30, 31].

GnRHST is a test method commonly used to diagnose CPP [5]. The test is used to evaluate the activity of the hypothalamic-pituitary axis by measuring the amount of releasing concentration of LH and FSH. GnRHST is

Table 3 Predictors of the precocious pubertal response, including the univariate and adjusted odd ratio and 95\% confidence limits according to maxillary dental developmental abnormalities

\begin{tabular}{|c|c|c|}
\hline \multirow{2}{*}{$\begin{array}{l}\text { Control group vs } \\
\text { CPP group }\end{array}$} & \multicolumn{2}{|c|}{ Odd ratio $(95 \% \mathrm{Cl})$} \\
\hline & Unadjusted $^{\mathbf{a}}$ & Adjusted $^{\mathbf{b}}$ \\
\hline Maxillary DDAs & $3.85(1.92-6.92)$ & $3.36(1.60-7.05)$ \\
\hline Mesiodens & $4.98(2.46-10.06)$ & $5.52(2.29-13.28)$ \\
\hline Except mesiodens & $1.39(0.43-4.44)$ & \\
\hline
\end{tabular}

Abbreviations: $C P P$ central precocious puberty, $\mathrm{Cl}$ confidence interval, $D D A s$ dental developmental abnormalities

aUnivariate logistic regression

${ }^{\mathrm{b}}$ Adjustment of age and sex 
considered invasive given the patients' ages because the test requires two to three consecutive blood tests separated by intervals of $15-30 \mathrm{~min}$ [5]. For this reason, a screening examination is performed by evaluating the bone age using a hand-wrist radiograph [19]. In the present study, the control group included patients whose bone age (as determined using the Greulich-Pyle atlas method) did not exceed the chronological age. Among the patients with an advanced bone age than chronological age, the CPP and PPP groups were classified based on the peak LH above 5 lU/L [4].

The CPP group had a significantly higher prevalence of maxillary DDAs than the control or PPP groups. Statistical analysis was performed between the CPP and control groups with an adjustment for sex and age because the proportion of girls was higher in the CPP group at $90.38 \%$, but no sex difference was observed in the control group at $55.90 \%$. The prevalence of maxillary DDAs was higher in the CPP group; regression analysis showed that the odds of maxillary DDAs in this group were 3.36 times higher than in the control group (confidence interval; CI, 1.60-7.05). In addition, mesiodens was remarkably prevalent in the CPP group, and the odds ratio of mesiodens was 4.98 times higher $(\mathrm{CI}, 2.46-10.06)$ in the CPP group. After sex and age-adjusted regression analysis, the odds ratio increased to 5.52 times higher (CI, 2.29-13.28) for mesiodens in the CPP group than the control group (Table 3). As a consequence, mesiodens could be considered a strong predictor of the development of CPP. As the CNS problem becomes a wellknown risk factor for PP, CPP boys were frequently found among the CNS problem patients [8]. Similarly, mesiodens could be used to predict CPP in boys who may not be diagnosed. Furthermore, CPP might be determined at the gestation period because mesiodens is developed around at the 16th week of gestation [20].

Early diagnosis and treatment of DDA patients are also important for increasing spontaneous tooth eruption and reducing the need for additional orthodontic or surgical intervention as well as the development of psychosocial problems [17]. In this study, however, the average dental evaluation age of the patients was slightly later than those of the pediatric evaluation age. The authors indicate that they might miss the opportunity for the early diagnosis of maxillary DDAs because no associations between the DDAs and PP have been established. Therefore, patients diagnosed with CPP should be referred for a dental examination. Furthermore, it should be noted that maxillary DDA patients were at high risk of developing CPP. Thus, they need to be referred for a pediatric examination.

On the other hand, DDA has a prevalence of $5-19 \%$ in mixed-dentition juveniles. In DDA, the prevalence of supernumerary teeth is generally approximately $3 \%$ [17].
Compared to previous studies, the results of this study showed a high prevalence of DDA in all three study groups, which can be attributed to the retrospective single institutional study design. Because not every patient with mesiodens was simultaneously tested for bone age and precocious puberty, it could be possible that the mesiodens patients were not evenly distributed among the groups. In addition, the risk of PP in boys with maxillary DDA could not be evaluated because of the limited number of samples. This study had some limitations, such as small sample size, heterogeneous sex distribution, and retrospective cohort study. Further large-scale or prospective multicenter studies of the association between CPP and maxillary DDAs, particularly mesiodens, will be needed.

\section{Conclusions}

Maxillary DDA was associated in the CPP group compared with the PPP or control groups. In particular, mesiodens was associated significantly with the PP response, and could be considered a predictor of CPP development. A patient diagnosed with $\mathrm{CPP}$ needs to be referred for a dental examination, and those identified with mesiodens should be referred for a pediatric examination of CPP.

\section{Abbreviations \\ CPP: Central precocious puberty; Cl: Confidence interval; DDAs: Dental developmental abnormalities; PP: Precocious puberty; PPP: Peripheral precocious puberty}

\section{Acknowledgements}

Not applicable

\section{Authors' contributions}

Ku JK conceptualized the study and analyzed the data. Kim Y investigated the data and wrote the initial manuscript. Choi SK statistically analyzed the data. Jung HI, Lee NK, and Kim JH co-conceptualized the study. All authors revised and approved the final manuscript.

\section{Funding}

No financial or non-financial benefits have been received or will be received from any party related directly or indirectly to the subject of this article.

\section{Availability of data and materials \\ The datasets used during the current study are available from the corresponding author on reasonable request.}

\author{
Ethics approval and consent to participate \\ The study was reviewed and approved by the Institutional Review Board at \\ Seoul National University Bundang Hospital (No. B-1904/535-106) with waiver \\ of the informed consent. \\ Consent for publication \\ Not applicable \\ Competing interests \\ Not applicable \\ Author details \\ ${ }^{1}$ Department of Preventive Dentistry and Public Oral Health, Yonsei \\ University, Seoul, Korea. ${ }^{2}$ Department of Orthodontics, Section of Dentistry, \\ Seoul National University Bundang Hospital, Seongnam-si, Korea.
}


${ }^{3}$ Department of Pediatrics, Seoul National University Bundang Hospital, Seongnam-si, Korea. ${ }^{4}$ Department of Oral and Maxillofacial Surgery, Section of Dentistry, Armed Forces Medical Command, Armed Forces Capital Dental Hospital, Seongnam-si 13634, Korea. ${ }^{5}$ Department of Oral and Maxillofacial Surgery, Seoul Asan Medical Center, Seoul, Korea. ${ }^{6}$ Department of Biostatistics, Korea University College of Medicine, Seoul, Korea.

Received: 10 June 2020 Accepted: 12 August 2020

Published online: 26 August 2020

\section{References}

1. Rosenfield RL, Cooke DW, Radovick S (2014) Puberty and its disorders in the female. In: Pediatric Endocrinology, 4th edn. Elsevier Inc, 609, p 530

2. Satoh M (2015) Bone age: assessment methods and clinical applications. Clin Pediatr Endocrinol 24:143-152. https://doi.org/10.1297/cpe.24.143

3. Lazar L, Padoa A, Phillip M (2007) Growth pattern and final height after cessation of gonadotropin-suppressive therapy in girls with central sexual precocity. J Clin Endocrinol Metab 92:3483-3489. https://doi.org/10.1210/jc. 2007-0321

4. $\quad$ Kim HS (2008) Update of precocious puberty. J Korean Endocr Soc 23:165173. https://doi.org/10.3803/jkes.2008.23.3.165

5. Resende EA, Lara BH, Reis JD, Ferreira BP, Pereira GA, Borges MF (2007) Assessment of basal and gonadotropin-releasing hormone-stimulated gonadotropins by immunochemiluminometric and immunofluorometric assays in normal children. J Clin Endocrinol Metab 92:1424-1429. https://doi. org/10.1210/jc.2006-1569

6. Lee J, Kim J, Yang A, Cho SY, Jin DK (2018) Etiological trends in male central precocious puberty. Ann Pediatr Endocrinol Metab 23:75-80. https://doi.org/ 10.6065/apem.2018.23.2.75

7. Özen S, Darcan \$ (2011) Effects of environmental endocrine disruptors on pubertal development. J Clin Res Pediatr Endocrinol 3:1-6. https://doi.org/ 10.4274/jcrpe.v3i1.01

8. Topor LS, Bowerman K, Machan JT, Gilbert CL, Kangarloo T, Shaw ND (2018) Central precocious puberty in Boston boys: a 10-year single center experience. PLoS One 13:e0199019. https://doi.org/10.1371/journal.pone. 0199019

9. Roberts MW, Li SH, Comite F, Hench KD, Pescovitz OH, Cutler GB Jr, Loriaux DL (1985) Dental development in precocious puberty. J Dent Res 64:10841086. https://doi.org/10.1177/00220345850640081301

10. Lee HK, Choi SH, Fan D, Jang KM, Kim MS, Hwang CJ (2018) Evaluation of characteristics of the craniofacial complex and dental maturity in girls with central precocious puberty. Angle Orthod 88:582-589. https://doi.org/10. 2319/112317-809.

11. Gaethofs M, Verdonck A, Carels C, de Zegher F (1999) Delayed dental age in boys with constitutionally delayed puberty. Eur J Orthod 21:711-715. https://doi.org/10.1093/ejo/21.6.711

12. de Paula Junior DF, Mendonca EF, da Costa PSS, Leles CR (2018) Malocclusion and maxillofacial characteristics of young girls having precocious puberty. Int J Paediatr Dent 28:540-546. https://doi.org/10.1111/ ipd. 12374

13. Klein OD, Oberoi S, Huysseune A, Hovorakova M, Peterka M, Peterkova R (2013) Developmental disorders of the dentition: an update. Am J Med Genet C: Semin Med Genet 163C:318-332. https://doi.org/10.1002/ajmg.c. 31382

14. Syriac G, Joseph E, Rupesh S, Philip J, Cherian SA, Mathew J (2017) Prevalence, characteristics, and complications of supernumerary teeth in nonsyndromic pediatric population of South India: a clinical and radiographic study. J Pharm Bioallied Sci 9:S231-S236. https://doi.org/10 4103/jpbs.JPBS_154_17

15. Simic S, Pavlovic J, Nikolić P, Vujacic A, Vukicevic V, Jovanovic R (2017) The prevalence of peg-shaped and missing lateral incisors with maxillary impacted canines. Vojnosanit Pregl 76:61. https://doi.org/10.2298/ VSP170225079S

16. Sajnani AK, King NM (2014) Dental anomalies associated with buccally- and palatally-impacted maxillary canines. J Investig Clin Dent 5:208-213. https:// doi.org/10.1111/jicd.12035

17. Shih WY, Hsieh CY, Tsai TP (2016) Clinical evaluation of the timing of mesiodens removal. J Chin Med Assoc 79:345-350. https://doi.org/10.1016/j. jcma.2015.10.013

18. Klein KO, Barnes KM, Jones JV, Feuillan PP, Cutler GB Jr (2001) Increased final height in precocious puberty after long-term treatment with $\mathrm{LHRH}$ agonists: the National Institutes of Health experience. J Clin Endocrinol Metab 86: 4711-4716. https://doi.org/10.1210/jcem.86.10.7915

19. Baik JS, Choi JW, Kim SJ, Kim JH, Kim S, Kim JH (2017) Predictive value of dental maturity for a positive gonadotropin-releasing hormone stimulation test result in girls with precocious puberty. J Korean Med Sci 32:296-302. https://doi.org/10.3346/jkms.2017.32.2.296

20. Qamar CR, Bajwa Jl, Rahbar MI (2013) Mesiodens-etiology, prevalence, diagnosis and management. Pak Orthod J 5:73-76

21. Kjaer I (2015) Sella turcica morphology and the pituitary gland-a new contribution to craniofacial diagnostics based on histology and neuroradiology. Eur J Orthod 37:28-36. https://doi.org/10.1093/ejo/cjs091

22. Kjaer I (2010) Orthodontics and foetal pathology: a personal view on craniofacial patterning. Eur J Orthod 32:140-147. https://doi.org/10.1093/ ejo/cjp059

23. Leonardi R, Barbato E, Vichi M, Caltabiano M (2009) Skeletal anomalies and normal variants in patients with palatally displaced canines. Angle Orthod 79:727-732. https://doi.org/10.2319/082408-448.1

24. Korayem M, AlKofide E (2015) Size and shape of the sella turcica in subjects with Down syndrome. Orthod Craniofacial Res 18:43-50. https://doi.org/10. 1111/ocr.12059

25. Ali B, Shaikh A, Fida M (2014) Association between sella turcica bridging and palatal canine impaction. Am J Orthod Dentofac Orthop 146:437-441. https://doi.org/10.1016/j.ajodo.2014.06.010

26. Leonardi R, Barbato E, Vichi M, Caltabiano M (2006) A sella turcica bridge in subjects with dental anomalies. Eur J Orthod 28:580-585. https://doi.org/10. 1093/ejo/cjl032

27. Kjellberg H, Beiring M, Albertsson Wikland K (2000) Craniofacial morphology, dental occlusion, tooth eruption, and dental maturity in boys of short stature with or without growth hormone deficiency. Eur J Oral Sci 108:359367. https://doi.org/10.1034/j.1600-0722.2000.108005359.x

28. Cantu G, Buschang PH, Gonzalez JL (1997) Differential growth and maturation in idiopathic growth-hormone-deficient children. Eur J Orthod 19:131-139. https://doi.org/10.1093/ejo/19.2.131

29. Demirjian A, Buschang PH, Tanguay R, Patterson DK (1985) Interrelationships among measures of somatic, skeletal, dental, and sexual maturity. Am J Orthod 88:433-438. https://doi.org/10.1016/0002-9416(85)90070-3

30. Ito RK, Vig KW, Garn SM, Hopwood NJ, Loos PJ, Spalding PM, Deputy BS, Hoard BC (1993) The influence of growth hormone (rhGH) therapy on tooth formation in idiopathic short statured children. Am J Orthod Dentofac Orthop 103:358-364. https://doi.org/10.1016/0889-5406(93)70017-I

31. Van Erum R, Mulier G, Carels C, de Zegher F (1998) Craniofacial growth and dental maturation in short children born small for gestational age: effect of growth hormone treatment. Own observations and review of the literature. Horm Res 50:141-146. https://doi.org/10.1159/000023262

\section{Publisher's Note}

Springer Nature remains neutral with regard to jurisdictional claims in published maps and institutional affiliations.

\section{Submit your manuscript to a SpringerOpen ${ }^{\circ}$ journal and benefit from:}

- Convenient online submission

- Rigorous peer review

- Open access: articles freely available online

- High visibility within the field

- Retaining the copyright to your article

Submit your next manuscript at $>$ springeropen.com 